\title{
Characterization of deep aquifer dynamics using principal component analysis of sequential multilevel data
}

\author{
D. Kurtzman ${ }^{1}$, L. Netzer ${ }^{2}$, N. Weisbrod ${ }^{2}$, A. Nasser ${ }^{1}$, E. R. Graber ${ }^{1}$, and D. Ronen ${ }^{2,3}$ \\ ${ }^{1}$ Institute of Soil, Water and Environmental Sciences, The Volcani Center, Agricultural Research Organization, \\ P.O. Box 6, Bet Dagan 50250, Israel \\ ${ }^{2}$ Department of Hydrology \& Microbiology, Zuckerberg Institute for Water Research, Blaustein Institutes for \\ Desert Research, Ben Gurion University of the Negev, Sde Boker Campus, Negev 84990, Israel \\ ${ }^{3}$ Hydrological Service and Water Quality Division, Israel Water Authority, P.O. Box 20365, Tel Aviv 61203, Israel
}

Correspondence to: D. Kurtzman (daniel@volcani.agri.gov.il)

Received: 16 September 2011 - Published in Hydrol. Earth Syst. Sci. Discuss.: 25 October 2011

Revised: 14 February 2012 - Accepted: 22 February 2012 - Published: 8 March 2012

\begin{abstract}
Two sequential multilevel profiles were obtained in an observation well opened to a 130-m thick, unconfined, contaminated aquifer in Tel Aviv, Israel. While the general profile characteristics of major ions, trace elements, and volatile organic compounds were maintained in the two sampling campaigns conducted 295 days apart, the vertical locations of high concentration gradients were shifted between the two profiles. Principal component analysis (PCA) of the chemical variables resulted in a first principal component which was responsible for $\sim 60 \%$ of the variability, and was highly correlated with depth. PCA revealed three distinct depth-dependent water bodies in both multilevel profiles, which were found to have shifted vertically between the sampling events. This shift cut across a clayey bed which separated the top and intermediate water bodies in the first profile, and was located entirely within the intermediate water body in the second profile. Continuous electrical conductivity monitoring in a packed-off section of the observation well revealed an event in which a distinct water body flowed through the monitored section $\left(v \sim 150 \mathrm{~m} \mathrm{yr}^{-1}\right)$. It was concluded that the observed changes in the profiles result from dominantly lateral flow of water bodies in the aquifer rather than vertical flow. The significance of this study is twofold: (a) it demonstrates the utility of sequential multilevel observations from deep wells and the efficacy of PCA for evaluating the data; (b) the fact that distinct water bodies of 10 to $100 \mathrm{~m}$ vertical and horizontal dimensions flow under contaminated sites, which has implications for monitoring and remediation.
\end{abstract}

\section{Introduction}

Multilevel sampling (MLS) has been found useful for improving hydrochemical and hydraulic characterizations of aquifers relative to other sampling methods (Ronen et al., 1986; Cherry et al., 2007; Müller et al., 2010; Kurtzman et al., 2011). Depth-dependent samples from deep aquifers are usually obtained during drilling (Williams and Chou, 2007; Hendry et al., 2011); hence interpretation of aquifer dynamics from these single-time data sets is limited. In the present study we explored deep aquifer dynamics using a unique set of observations from two sequential MLS campaigns. Depthdependent groundwater samples were obtained from a customized monitoring well at a contaminated industrial site located in the Coastal Aquifer of Israel (Graber et al., 2008). Significant vertical variability in the chemical composition of groundwater at a single point in time had been described by Netzer et al. (2011). In the current study, we analyzed the aquifer dynamics that might explain differences in the observed hydrochemical vertical distributions obtained in consecutive MLS campaigns. The analysis included delineation of discrete water bodies, consideration of vertical and lateral flow, and assessment of hydrostratigraphic separation. Principal component analysis (PCA) was employed to examine the depth- and time-dependent chemical variables from the two multilevel profiles. Groundwater electrical conductivity (EC) and head measurements provided the necessary background for interpreting the flow dynamics that were responsible for the temporal changes in hydrochemical profiles.

PCA is a multivariate statistical procedure usually used for exploratory data analysis. It transforms a large number of possibly correlated variables into a smaller number of uncorrelated (orthogonal) variables called principal components

Published by Copernicus Publications on behalf of the European Geosciences Union. 
(PCs). The PCs account for as much of the variability in the data as possible, with the first PC explaining the greatest proportion of the variability, and each succeeding PC explaining the next largest proportion (StatSoft Inc., 2011). PCA of major ions and trace elements has been used to evaluate recharge in a karst aquifer and groundwater flow in a regional aquifer (Moore et al., 2009; Stetzenbach et al., 1999, respectively). Angelone et al. (2009) used PCA of major ions and trace elements from wells in an area of $900 \mathrm{~km}^{2}$ to verify the source of arsenic-rich water. However, to the best of our knowledge, PCA has never been used to analyze time- and depthdependent hydrochemical data sets from a single deep well.

\section{Materials and methods}

\subsection{Aquifer, site and observation well}

A 150-m deep observation well designed for MLS extends throughout the entire vertical section of the Coastal Aquifer in Tel Aviv $\left(32^{\circ} 04^{\prime} 21^{\prime \prime} \mathrm{N}, 34^{\circ} 47^{\prime} 58^{\prime \prime} \mathrm{E}\right)$. The Coastal Aquifer of Israel is an unconfined sandy-sandstone aquifer that stretches over an area of $\sim 2000 \mathrm{~km}^{2}$ running parallel to the Mediterranean coast. It exhibits a wedge-like shape from the coast inland, reaching a maximum thickness of 150 to $180 \mathrm{~m}$ in the west (Fig. 1). The aquifer is composed of Pleistocene sand and calcareous sandstone interleaved with discontinuous lower-permeability marine and continental silt and clay lenses (Issar, 1980). Thick Neogene clay known as the Saqiye Group underlies the aquifer (Fig. 1). The Coastal Aquifer is one of the three most important natural freshwater resources in Israel. Due to its large storage capacity and sandy characteristics, it hosts many artificial recharge operations (e.g. soil-aquifer treatment of Tel Aviv metropolis wastewater, amounting to $\sim 130 \times 10^{6} \mathrm{~m}^{3} \mathrm{yr}^{-1}$ ), and serves as a national-scale multiyear reservoir (i.e. stores reserves in water-rich periods and is mined in periods of water stress).

The Coastal Aquifer has undergone substantial changes in water quality in the Tel Aviv metropolitan area over the course of its urbanization. In the middle of the 20th century, the main water-quality issues were: (1) salinization due to intensive water mining that led to seawater encroachment, and (2) increasing nitrate concentrations caused by the rapid increase in population before construction of a piped sewage system (Zilberbrand et al., 2001). Since the 1990s, the main groundwater concern in the aquifer underlying the Tel Aviv metropolitan area is industrial contaminants.

At the research site, extensive and intensive contamination of the unsaturated zone and groundwater with chlorinated organic compounds and heavy metals has been reported (Ronen et al., 2005; Graber et al., 2008). The deep observation well was drilled to explore the vertical distribution of contaminants at the center of the plume. The drilling revealed a 6-m thick clayey bed between 73 and $79 \mathrm{~m}$ below ground level (m b.g.l.) (Fig. 2). Clayey beds (lenses) at these depths in this part of the aquifer are usually of continental origin and may be discontinuous over short distances (Ecker, 1999). Nevertheless, some studies have shown that this type of beds can create effective hydraulic separation (e.g. Nativ and Weisbrod, 1994). At the monitoring location, the full saturated thickness of the aquifer is $\sim 130 \mathrm{~m}$ from the water table to the bottom confining Saqiye Group clays (Figs. 1 and 2). The monitoring well was drilled with a percussion tool and no drilling mud. It was designed to ensure reliable deep MLS by inserting bentonite and PVC seals into the sand-pack between and within perforated sections (Fig. 2). Two separate pipes, one tapping the deep part of the aquifer between 79 and $149 \mathrm{~m}$ b.g.l. (D, Fig. 2), and one tapping the shallow part of the aquifer between 18 and $72 \mathrm{mb}$ b.g.l. (S, Fig. 2), were installed in the borehole to avoid cross-contamination between the two parts of the aquifer.

\subsection{MLS campaigns and chemical analyses}

Groundwater samples were obtained using previously described passive MLS methodology (Ronen et al., 1986; Laor et al., 2003; Kurtzman et al., 2011). Briefly, each sampling unit consists of an individual stainless steel cylindrical dialysis cell $(150 \mathrm{ml})$; the sampling units can be attached in a modular fashion, connected to each other with a chain. Each unit has a stainless steel ring into which the dialysis cell is inserted. The dialysis cells are confined between flexible Viton seals that fit into the inner diameter of the well screen, creating a 12-cm sampling interval per cell. Before the chain of passive samplers is lowered into the well, the cells are filled with distilled water and closed on both sides with dialysis membrane (Versapor membrane, PALL corporation, $0.2 \mu \mathrm{m}$ ) crimped in a PVC hoop with a Viton O-ring.

Two multilevel profiles were obtained in the observation well. In the first sampling campaign (MLS1), the chain of sampling cells was deployed on 15 July 2008 and retrieved on 10 August 2008. In the second sampling campaign (MLS2), the cells were deployed on 5 February 2009 and retrieved on 1 June 2009. The retrieval date was regarded as the sampling date because the equilibration time of the dialysis cell with well water is short relative to the residence time of the cells in the well ( $\sim 48 \mathrm{~h}$, Netzer et al., 2011). The minimum residence time required to ensure resumption of normal flow conditions has been estimated at 3 weeks (Netzer et al., 2011).

MLS1 included 17 sampling depths, and MLS2 included 24 sampling depths (Fig. 3). The number of dialysis cells at each sampling depth $(1,2$ or 3$)$ is shown in Fig. 3. Volatile organic compounds (VOCs) were not analyzed at sampling depths with only one dialysis cell. The lowermost section of the aquifer (near the Saqiye clay) was densely sampled. Results of MLS1 influenced the configuration (depth location and number of dialysis cells) of MLS2. Samples for VOC and heavy metal analysis were preserved with 4 drops 

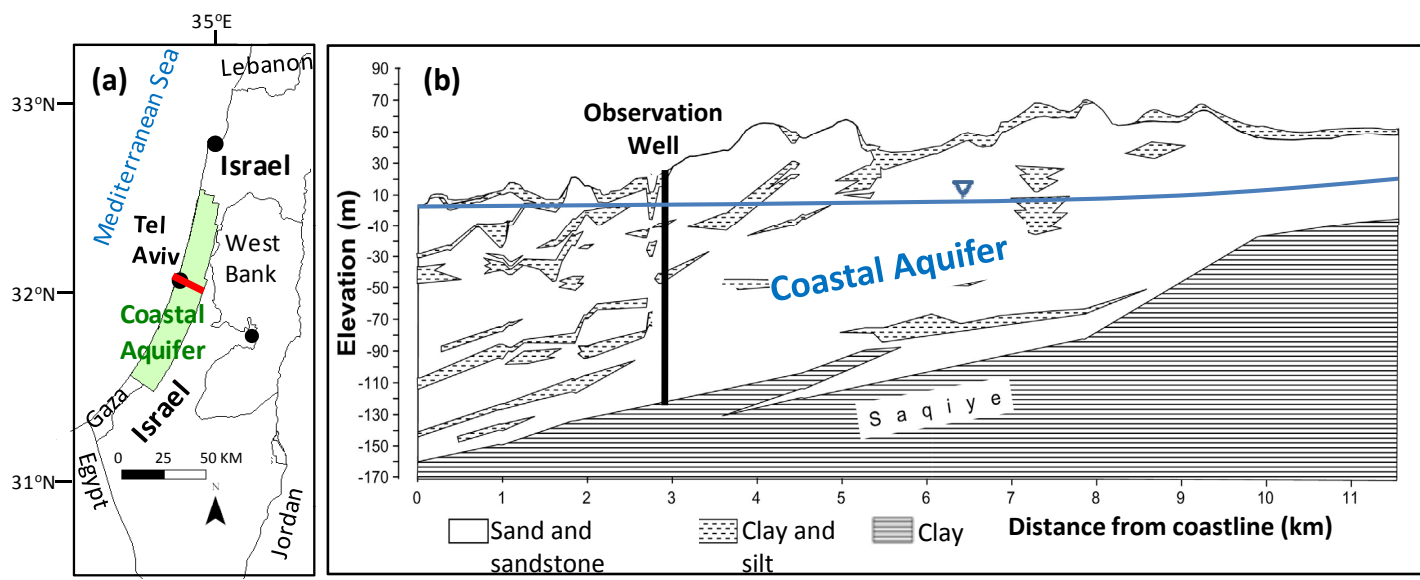

Fig. 1. (a) Location map of the Israeli Coastal Aquifer (green). A cross section (red line) through the Tel Aviv metropolitan area is shown in (b). (b) East-west cross section of the aquifer, and the location of the observation well.

of $6 \mathrm{~N} \mathrm{HCl}$ and 3 drops of concentrated $\mathrm{HNO}_{3}$, respectively. The samples were stored at $4{ }^{\circ} \mathrm{C}$ until analysis, which was performed within 10 days.

Major anions were determined by ion chromatography (Dionex, Eluent Generator ICS-2500), major cations by ICPMS (Thermo Jarrell, Ash-61) for MLS1, and by ICP OES (Varian, 720-ES) for MLS2, and trace elements were determined by ICP-MS. Bicarbonate $\left(\mathrm{HCO}_{3}^{-}\right)$was determined by potentiometric titration with $0.002 \mathrm{NHCl}$ using a Radiometer Titralab titrator. VOCs were determined by GC/MS headspace after addition of internal standard and 1:5 dilution (Netzer et al., 2011) using a Combi PAL Auto sampler (CTC Analytics), a 6890N network GC system (Agilent Technologies) and a 5973 network Mass Selective Detector (Agilent Technologies). Dissolved organic carbon (DOC) (MLS2 only) was analyzed by Formacs TOC analyzer after sample acidification to $\mathrm{pH} 3.5$ and air bubbling for $2 \mathrm{~min}$. Chemical analyses were performed at the laboratories of the Agricultural Research Organization, Israel, and the Israel Water Authority.

Two types of error can affect the determined concentrations: analytical and retrieval. Retrieval errors are unique to the specific deep MLS setting reported here, and may be significant in deep samples due to the time it takes to retrieve the deep dialysis cells. During retrieval, these cells may be in contact for short times (up to $75 \mathrm{~min}$ for the deepest samples, Ronen et al., 2010) with water that is not from the interval they sampled. Examples of total relative errors (sum of analytical and retrieval errors) are 2 to $12 \%$ for $\mathrm{Cl}^{-}$and 12 to $21 \%$ for trichloroethylene (TCE), where the higher errors are for the deeper samples (Ronen et al., 2010). In this report however, interpretations were focused on concentration differences with depth and time that were significantly larger than these errors.

\subsection{Groundwater head and EC measurements}

Head was measured in the deep (D) and shallow (S) pipes of the observation well (Fig. 2) 25 times between April 2008 and October 2009. A combined water level-temperatureconductivity logger (LTC, Solinst ${ }^{\circledR}$ ) was inserted between Viton seals (similar to one interval of the MLS apparatus) and deployed at different depths (19, 20 and $31.5 \mathrm{mb}$ b.g.l.). The confined vertical length between the two seals was $35 \mathrm{~cm}$. Water level, temperature and $\mathrm{EC}$ were recorded every $30 \mathrm{~min}$.

\subsection{Principal component analysis (PCA)}

The groundwater-chemical variables were analyzed by PCA for the 17 sampling depths (in statistical terminology, 17 cases) of MLS1 and the 24 cases of MLS2 (Fig. 2). For MLS1, 23 variables were used for analysis: $\mathrm{Na}^{+}, \mathrm{K}^{+}, \mathrm{Mg}^{2+}$, $\mathrm{Ca}^{2+}, \mathrm{Cl}^{-}, \mathrm{SO}_{4}^{2-}, \mathrm{HCO}_{3}^{-}, \mathrm{NO}_{3}^{-}, \mathrm{Br}^{-}, \mathrm{As}, \mathrm{Al}, \mathrm{B}, \mathrm{Be}, \mathrm{Ba}, \mathrm{Co}$, $\mathrm{Cr}, \mathrm{Mn}^{2+}, \mathrm{Ni}, \mathrm{Pb}, \mathrm{Se}, \mathrm{Sr}, \mathrm{U}$ and total dissolved solids (TDS) (where no oxidation state is specified, analysis was of the total element). The same variables were utilized in the PCA of MLS2 except for $\mathrm{Pb}, \mathrm{Ni}$ and As (concentrations below the limit of quantification in most cases) and $\mathrm{Al}$ (not analyzed). One additional variable considered in MLS2 was DOC. The total number of variables for the PCA of MLS2 was therefore 20 . VOCs, analyzed at only 12 and 15 depths in MLS1 and MLS2, respectively, were not included in the PCA. PCA was performed with Statistica software using correlation matrices (StatSoft, 2011). 


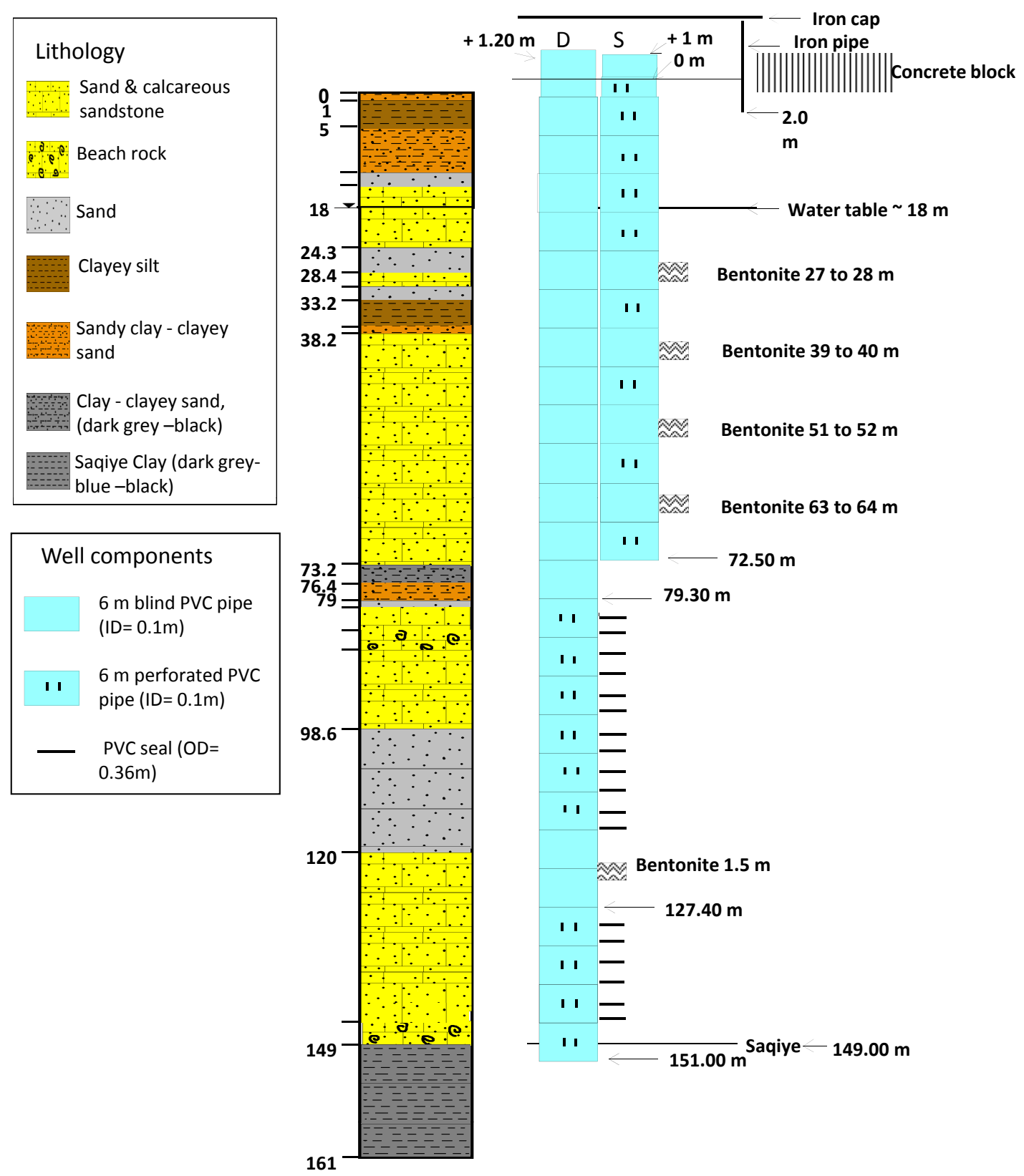

Fig. 2. Lithological log and perforation details of the observation well used for sequential multilevel sampling (MLS). D - pipe perforated against the deep subaquifer (79-149 m); $\mathrm{S}$ - pipe perforated against the shallow subaquifer (18-72 m); all depths are relative to ground level.

\section{Results}

\subsection{MLS profiles}

Profile pairs (MLS1 and MLS2) of eight representative chemical variables are presented in Fig. 4. The main characteristics of each chemical profile over the 130-m thick aquifer were preserved in both sampling events (Fig. 4). These general profile traits can be classified into five characteristic types: (a) concentrations generally increase with depth (e.g.
$\mathrm{Na}^{+}$and $\mathrm{Cl}^{-}$, Fig. 4c and d); (b) concentrations generally decrease with depth (e.g. $\mathrm{SO}_{4}^{2-}$, Fig. 4b); (c) concentrations generally increase with depth but decrease near aquifer bottom (e.g. $\mathrm{Mg}^{2+}$, Fig. 4a); (d) concentrations generally decrease with depth but increase near aquifer bottom (e.g. Co, Fig. 4f); (e) extremely high concentrations in the shallow part of the aquifer to orders of magnitude lower concentrations in the deep aquifer (e.g. Cr, TCE and tetrachloroethylene (PCE), Fig. 4e, g, and h). Profile types (a)-(d) were considered in the PCA (Sect. 3.3). 

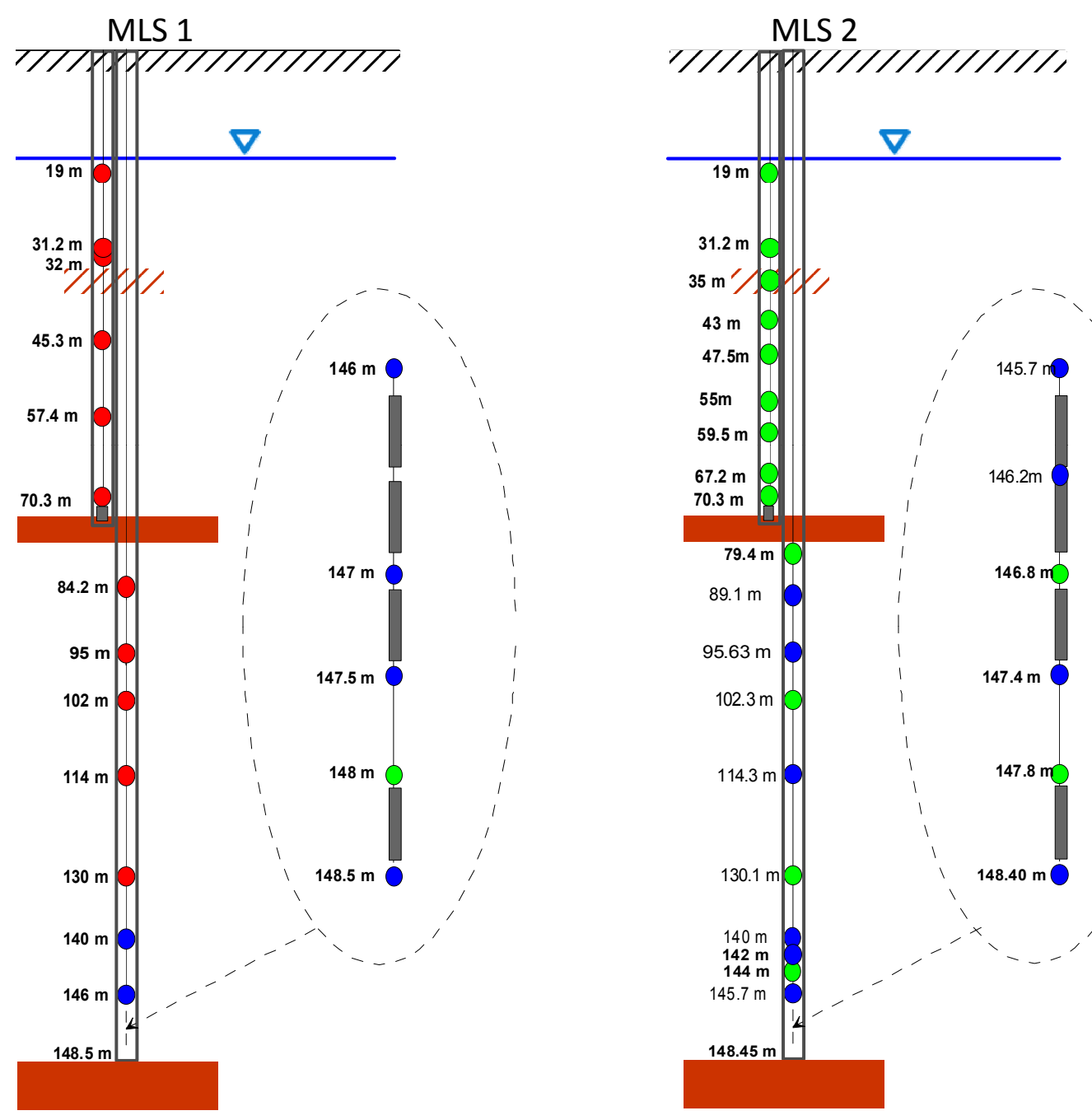

Fig. 3. Depth in meters below ground level (m b.g.1.) showing the positioning of the multilevel sampling (MLS) units in the two campaigns. Blue -1 cell per depth (major ion and trace element analysis), green -2 cells per depth and red -3 cells per depth (major ion, trace element and volatile organic compound analyses). The dotted inset denotes details of the MLS below $145 \mathrm{~m}$. Gray rectangles resemble weights that were inserted in the bottom of the chain of sampling cells to lead it down the well.

Despite the general similarities in chemical trends in the MLS1 and MLS2 profiles, a detailed examination revealed distinct differences between them. The most pronounced difference was the upward vertical shift of the boundary between concentrations typical to the upper part of the aquifer and concentrations typical to the lower part of the aquifer for many of the chemical variables (e.g. $\mathrm{Mg}^{2+}, \mathrm{SO}_{4}^{2-}, \mathrm{Cr}$, Co, TCE, and PCE, Fig. 4a, b, e-h). In MLS1, the boundary was consistent with stratigraphy, falling between the sampling depths of 70.3 and $84.2 \mathrm{mb}$ b.g.l., the interval that contains the 6-m thick clayey layer (Fig. 2), with $\mathrm{Cr}$ being the only exception. In MLS2, this hydrochemical boundary appeared to lie between 59.5 and $67.2 \mathrm{~m}$ b.g.l., i.e. within the upper sandy subaquifer (Figs. 3 and 4a, b, e-h).
Whereas the temporal shift in the hydrochemical boundary between the shallower and deeper waters was not seen in the $\mathrm{Na}^{+}$and $\mathrm{Cl}^{-}$profiles (Fig. 4c and d), there was a clear change in the depth of the highest concentration gradients within the deep subaquifer. In MLS1, they occurred in the 84-96 m interval whereas in MLS2, they occurred between 102 and $114 \mathrm{~m}$ (Fig. 4c and d). These large concentration gradients in the $102-114 \mathrm{~m}$ interval, which were observed only in MLS2, have also been noted for other variables $\left(\mathrm{NO}_{3}^{-}, \mathrm{Br}^{-}\right.$, B; Ronen et al., 2010), and are clearly depicted in the PCA (Sect. 3.3).

\subsection{Groundwater head and EC measurements}

During the period between MLS1 and MLS2, the groundwater head measured in the deep pipe (D, Fig. 2) was higher 

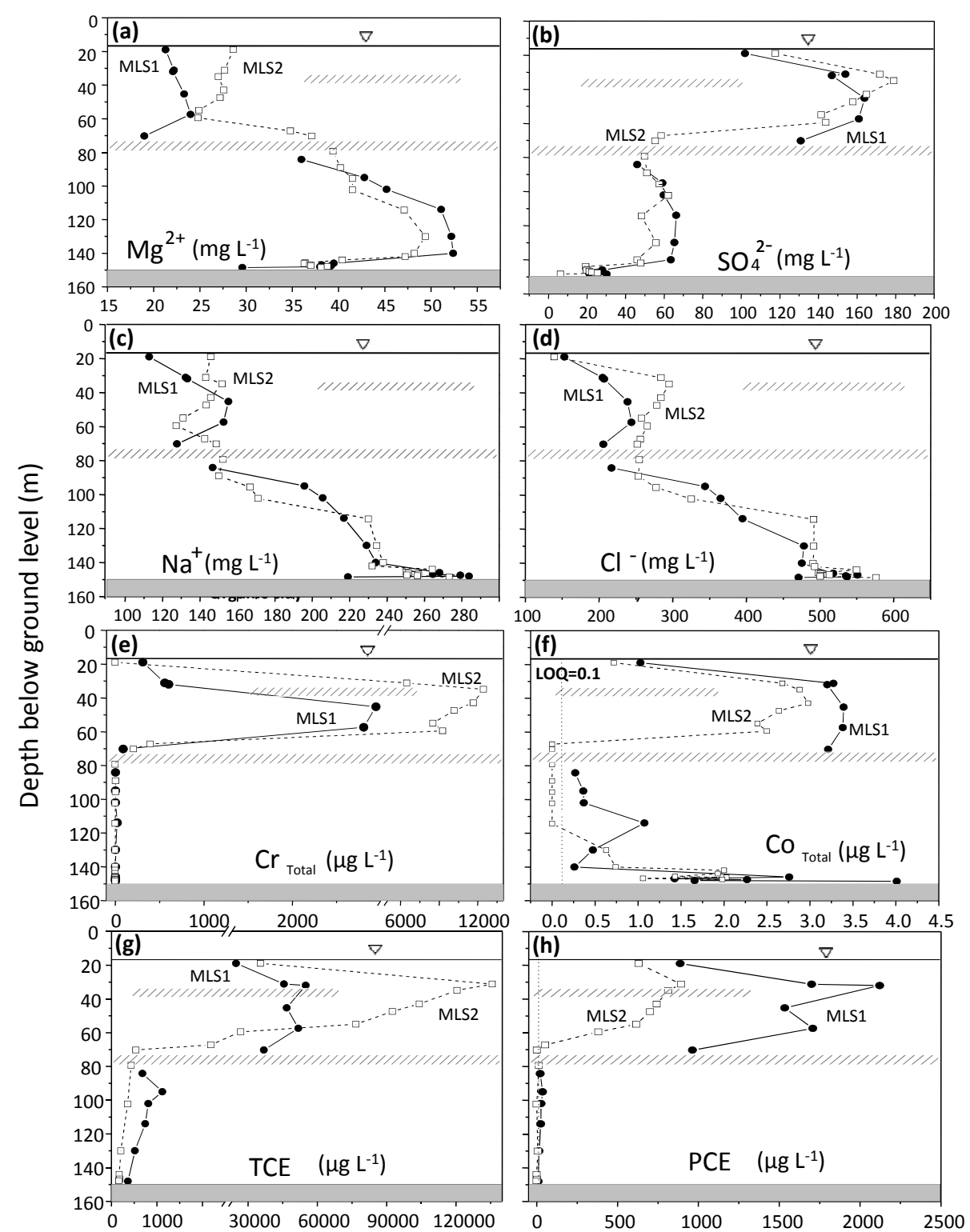

Fig. 4. Representative deep aquifer profiles obtained in sequential sampling campaigns. (a-d) major ions; (e, f) trace elements and (g, h) volatile organic compounds (VOCs). MLS1 (circles) obtained 10 August 2008; MLS2 (squares) obtained 1 June 2009. Saqiye Group clay in gray is the bottom aquifer boundary and clayey layers around 35 and $75 \mathrm{~m}$ depth are illustrated with dashed lines (Fig. 2). LOQ (f) - limit of quantification.

than that measured in the shallow pipe (S, Fig. 2) in 11 out of 12 measurements ( $\sim 97 \%$ of the time, Fig. 5). The difference between the overall head in the deep subaquifer and the head in the shallow subaquifer during the 295-day period ranged between -2 and $27 \mathrm{~cm}$ (Fig. 5). These data are suggestive of upward flow from the deep to shallow parts of the aquifer during the time interval between the two sampling dates. However, this is not a definitive interpretation, as these head measurements reflect the overall head in the tapped part of the aquifer rather than the specific head at a given point in the screened interval. Therefore, we can only conclude that, looking over the entire width of the aquifer during this period, the vertical component of flow was more upward than downward; we cannot draw any conclusion as to the prevailing flow at any specific depth.

EC was monitored in $35-\mathrm{cm}$ packed sections at three depths (19, 20 and $31.5 \mathrm{mb}$ b.g.l.) for 2 months prior to the deployment of MLS1. Although EC monitoring was not performed during the MLS campaign, some timedependent EC results at $31.5 \mathrm{~m}$ depth shed light on the aquifer's dynamics. An abrupt and significant decrease in EC $\left(\sim 0.6 \mathrm{mS} \mathrm{cm}^{-1}\right.$, Fig. 6) was observed once during the 


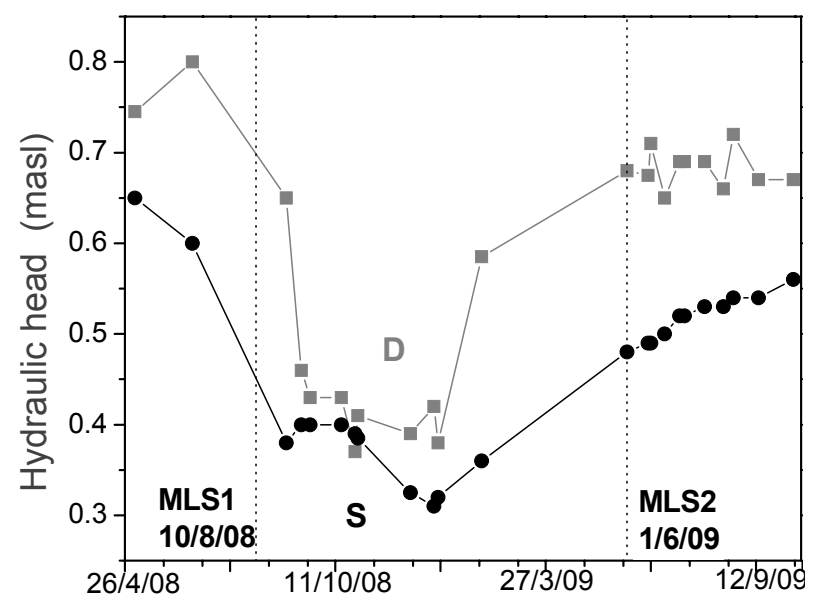

Fig. 5. Elevation of the hydraulic heads observed in the deep subaquifer in gray (measured in pipe D, Fig. 2) and the shallow subaquifer (measured in pipe S, Fig. 2). The dotted vertical lines denote the retrieval dates of MLS1 and MLS2. m a.s.l. - meters above sea level.

2 months of observations in which the LTC probe was positioned at the three depths $(\sim 3$ weeks per depth). Head and temperature, measured simultaneously, did not show any such contemporaneous discontinuities. Hence, the change can only be explained by lateral flow of a fresher water body through the monitored section. Changes in concentration in the packed-off section during this passage are caused by water from the interval with concentration $C$ leaving the interval and new water with lower concentration $C 2$ entering the interval (Eq. 1, Fig. 6).

$\frac{\mathrm{d} C}{\mathrm{~d} t}=-\frac{Q}{V}(C-C 2)$

where $t$ is time $(T), Q$ is flow rate through the interval $\left(L^{3} T^{-1}\right)$ and $V$ is the volume of the packed-off section (minus the probe volume) $\left(L^{3}\right)$. Equation (1) is similar to mass balance equations used for the interpretation of dilution tests (e.g. Brouyère et al., 2005; Kurtzman et al., 2005). The solution of Eq. (1) for our case is:

$\ln \left(\frac{C-C 2}{C 1-C 2}\right)=-\frac{Q}{V}(t-t 1)$

where $C 1$ and $t 1$ are the concentration and time, respectively, at the beginning of the concentration change (Fig. 6). Plotting the left-hand side of Eq. (2) against $t-t 1$ enables calculation of $-Q / V$ (the slope). Since $V$ is known, $Q$ can be determined. Groundwater specific discharge $-q\left(L T^{-1}\right)$ is derived by Eq. (3).

$q=\frac{Q}{L_{\mathrm{s}} D_{\mathrm{s}} \alpha}$

where $L_{\mathrm{s}}$ and $D_{\mathrm{S}}$ are the section's length and diameter, respectively $(L)$ and $\alpha(-)$ is a factor correcting for the convergence of the natural aquifer flow toward the well $(\alpha=2$ is

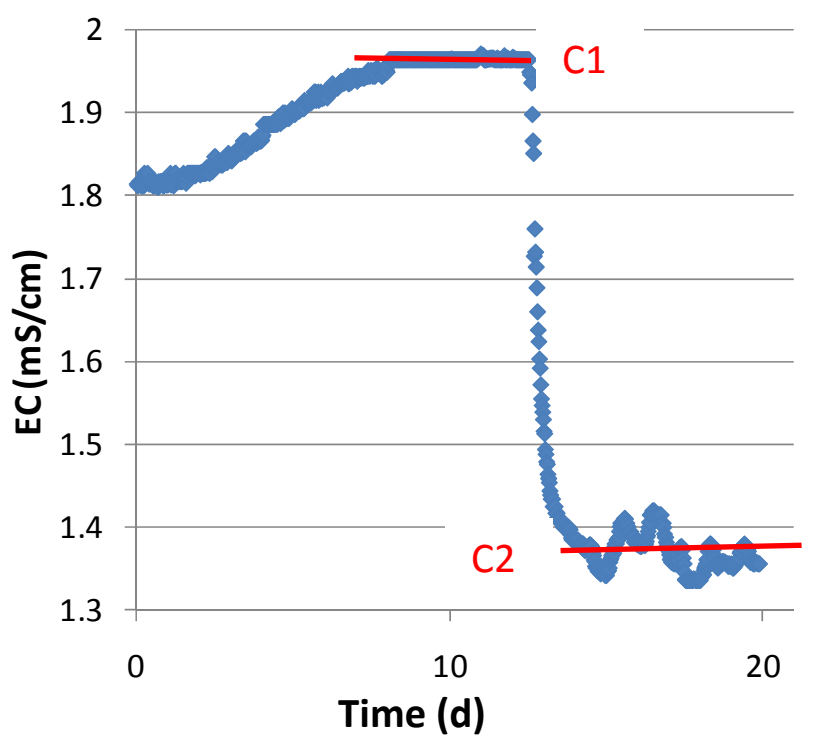

Fig. 6. Electrical conductivity (EC) monitored in a $35 \mathrm{~cm}$ packedoff section of the observation well at $31.5 \mathrm{~m}$ below ground level. Note the sharp change in EC on day 12, suggesting a relatively fresh water body flowed through the monitored section.

widely accepted and used here; e.g. Pitrak et al., 2007). This analysis resulted in $q \sim 40 \mathrm{~m} \mathrm{yr}^{-1}$. If we use an effective porosity of 0.25 for this aquifer (e.g. Assouline and Shavit, $2004)$, we have a groundwater velocity $(v)$ in the neighborhood of $v \sim 150 \mathrm{~m} \mathrm{yr}^{-1}$. This lateral velocity estimate suggests that some tens to hundred meters may laterally divide the water bodies sampled in MLS1 and MLS2. EC and chloride concentration from the two MLSs show a significant linear relation $\left(R^{2}=0.76\right.$, P value $\left.<1 \times 10^{-11}\right)$, hence the EC observations can be approximated as concentrations for the above calculations.

\subsection{PCA of the sequential MLS profiles}

In the following, results and interpretations concerning the main sources of variability, and water-body classification will be discussed using the projections of variables (chemicals) and cases (depths) on the plane of the first and second PCs (Fig. 7). The correlation of a variable with a PC is the value of that $\mathrm{PC}$ component in the variable projection onto the plane of the PCs. For example, in Fig. 7a we see that in the PCA of MLS1, the correlation of $\mathrm{Ca}^{2+}$ with PC1 (horizontal axis) is 0.84 and with PC2 (vertical axis), 0.03.

In both PCAs of MLS1 and MLS2, $\mathrm{Cl}^{-}, \mathrm{Na}^{+}, \mathrm{K}^{+}$have a high correlation with $\mathrm{PC} 1$ (negative correlation in MLS1 and positive in MLS2, Fig. 7a and b, respectively). These variables show a type (a) profile (concentrations generally increase with depth; Sect. 3.1) and are therefore referred to as type (a) variables. $\mathrm{Ca}^{2+}, \mathrm{NO}_{3}^{-}, \mathrm{SO}_{4}^{2-}$, which generally decrease with depth (type (b) variables) also show high 
(a) MLS1, variables projected on PC1-PC2 plane

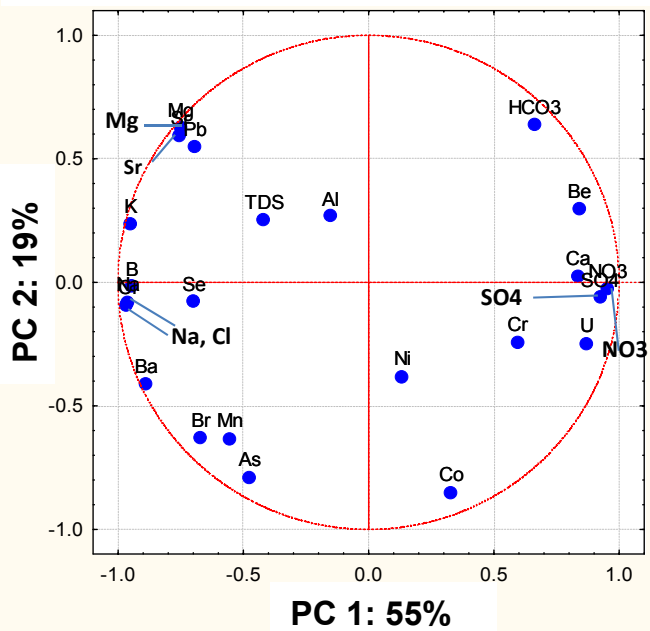

(c) MLS1, cases projected on PC1-PC2 plane

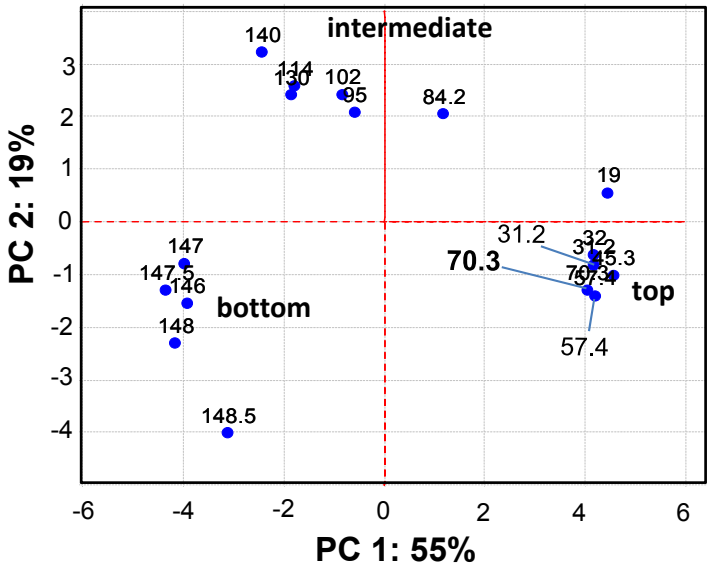

(b) MLS2, variables projected on PC1-PC2 plane

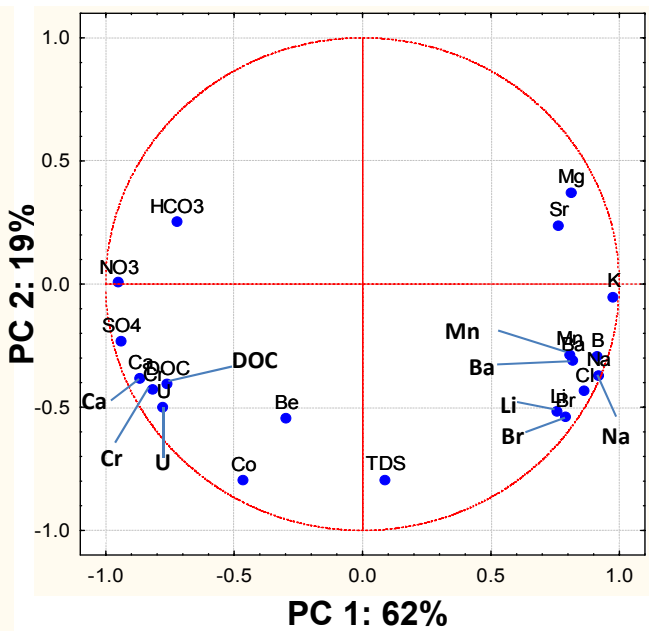

(d) MLS 2, cases projected on PC1-PC2 plane

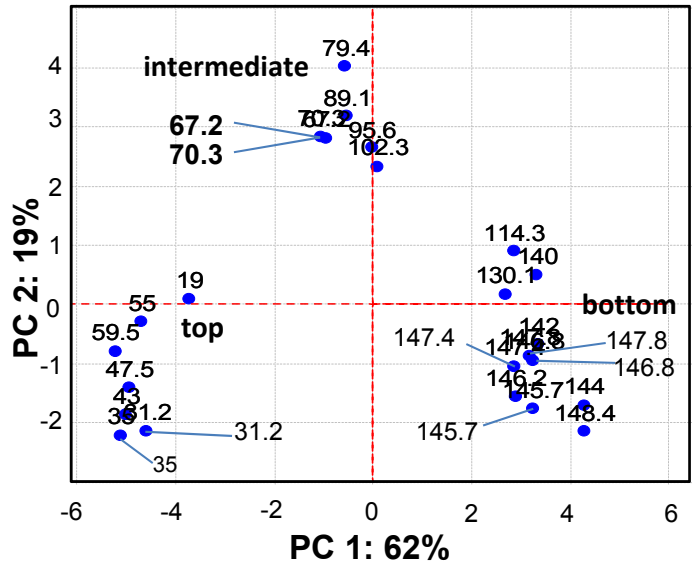

Fig. 7. Principal component analysis (PCA) of the multilevel sampling (MLS) campaigns. Variables (a, b) and cases (c, d) are projected on the plane of the first two principal components. Cases are labeled by the sampling depth in meters below ground level ( $\mathrm{m}$ b.g.1.). Top, intermediate and bottom groups of cases are distinct. Oxidation states of ions were omitted for graphical simplicity.

correlations with PC1, but with the opposite sign to that of the type (a) variables, in both MLS1 and MLS2 (Fig. 7a and b). These results suggest that PC1 in both PCAs is closely related to depth. Therefore the correlation of $\mathrm{PC} 1$ with depth (a type (a) variable), was calculated and found to be -0.97 in the PCA of MLS1 and 0.96 in the PCA of MLS2. PC1 explains $55 \%$ and $62 \%$ of the variability in MLS1 and MLS2, respectively (Fig. 7a and b); hence, we can postulate that depth is the major controller of chemical variability in the profile. This can also be visualized in the distribution of cases (depths) along the PC1 axis. Cases of the bottom part of the aquifer are on one side of the PC1 axis, whereas cases from the top of the aquifer are on the opposite side of the axis, while cases from the intermediate depths are close to 0 on this axis (Fig. 7c and d).
By definition, $\mathrm{PC} 2$ is orthogonal to $\mathrm{PC} 1$. Therefore, if $\mathrm{PC} 1$ is correlated with variables that show a relatively monotonous trend with depth (profile types (a) and (b)), PC2 is expected to be correlated with variables that have nonmonotonous profiles (profile types (c) and (d)). $\mathrm{Mg}^{2+}$ and Co are variables that were found to be relatively correlated with PC2 yet with an opposite sign in PCAs of MLS1 and MLS2 (i.e. have a high component of PC2 relative to other variables, Fig. 7a and b). The non-monotonous profiles of $\mathrm{Mg}^{2+}$ and $\mathrm{Co}$ are depicted in Fig. $4 \mathrm{a}$ and $\mathrm{f}: \mathrm{Mg}^{2+}$ has a low-high-low (type (c)) profile whereas Co shows a mirrorimage high-low-high (type (d)) profile. The absolute correlation of $\mathrm{Mg}^{2+}$ with $\mathrm{PC} 2$ is smaller than that of $\mathrm{Co}$ and it also has a relatively high correlation with $\mathrm{PC} 1$, and it is therefore not as good an example as Co to infer PC2 characteristics; nevertheless, it is the best available example, having a 
relatively high positive correlation with PC2 in both MLS1 and MLS2 (Fig. 7a and b). The physical phenomenon that has a greater impact on PC2 is the abrupt change in concentration that was found for some variables near the bottom of the aquifer. These variables include metals such as $\mathrm{Mn}^{2+}$, $\mathrm{Co}$, As (increase in concentration near the bottom) and major ions $\mathrm{Mg}^{2+}, \mathrm{HCO}_{3}^{-}, \mathrm{SO}_{4}^{2-}$ (decrease in concentration near the bottom) (Ronen et al., 2010). These variables will have a relatively high correlation with PC2 if the abrupt change in concentration near the bottom of the aquifer is counter to the variables' general trend with depth, hence forming a nonmonotonous profile (e.g. compare profiles and PC2 correlations of $\mathrm{Mg}^{2+}$ and $\mathrm{SO}_{4}^{2-}$ in Figs. $4 \mathrm{a}, \mathrm{b}, 7 \mathrm{a}$ and b). In light of this analysis of PC2 (19\% of variability in both MLS1 and MLS2), it can be concluded that the second important control over chemical variability in the profile is the different hydrochemical conditions that prevail at the bottom of the aquifer.

Both MLS1 and MLS2 case projections show three distinct groups that are consistent with depth (Figs. 3, 7c and d). The clear distinction of three vertically separated water bodies in the PCAs of the MLS1 and MLS2 chemical data is the most significant outcome of the PCA for aquifer dynamics characterization. Hereafter, these three water bodies are denoted as top, intermediate and bottom (Fig. 7c and d).

A significant difference between the PCAs of MLS1 and MLS2 was that some sampling depths were in different water bodies: depths 67 and $70.3 \mathrm{~m}$ b.g.l. were in the top water body in MLS1 and were shifted to the intermediate one in MLS2. Depths 114, 130 and $140 \mathrm{mb}$ b.g.l. were in the intermediate water body in MLS1 and in the bottom water body (or at least much closer to it) in MLS2 (Fig. 7c and d). The boundary between the top and intermediate water bodies was between 70 and $84 \mathrm{~m}$ in MLS1 (consistent with stratigraphy, Fig. 2), whereas in MLS2, this boundary lay between 59 and $67 \mathrm{~m}$ b.g.l. It also appears that the boundary between the intermediate and bottom water bodies shifted from between 140 and $146 \mathrm{~m}$ b.g.l. in MLS1 to between 102 and $114 \mathrm{~m}$ b.g.l. in MLS2 (Fig. 7c, d). These changes in the position of the boundaries between the chemically different water bodies that could be obtained, to some extent, by exploring the profiles of MLS1 and MLS2 (Fig. 4) became sharper with the PCA (Fig. 7). A discussion of the aquifer dynamics that may have caused these vertical shifts of water-body boundaries follows.

\section{Discussion}

\subsection{Aquifer dynamics that can explain the change between MLS1 and MLS2}

Two possible "end member" flow regimes near the observation well were examined. Assuming a 1-D vertical system and neglecting changes in the concentrations of major and trace elements due to reactions during the 295 days between (a)

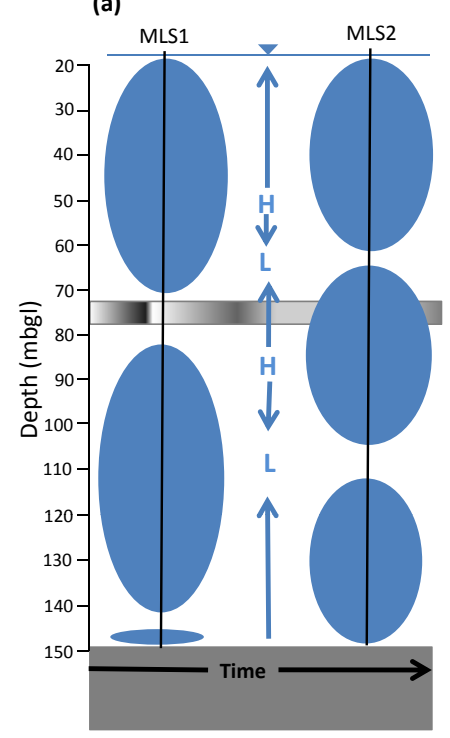

(b)

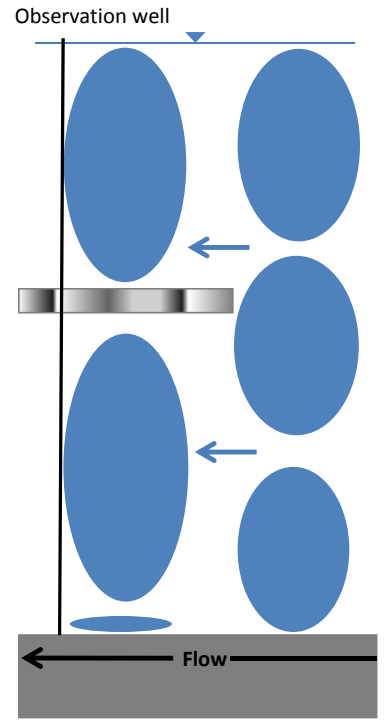

Fig. 8. Schematic representation of flow regime end members near the observation well. Blue ellipses present the water bodies inferred in the PCA of MLS1 (left) and MLS2 (right). (a) Vertical-dominant flow regime during the time between samplings that might support the differences in the vertical distribution of the water bodies observed in the two campaigns. " $\mathrm{L}$ " and " $\mathrm{H}$ " represent relatively low and high hydraulic heads, respectively. (b) Lateral flow of water bodies passing through the observation well as an alternative explanation of the differences. An arbitrary snapshot before MLS1 sampling date is presented. Note that MLS2 water bodies are assumed to originate from an area where the clayey bed at $73-79 \mathrm{~m} \mathrm{b.g.l}$. is absent.

MLS1 and MLS2, a vertical flow regime can be hypothesized to explain the changes in the vertical distribution of the three water bodies obtained by the PCA (Figs. 7c, d and 8a) as follows. The water from the bottom of the aquifer flowed upward to form a larger water body which is a mix of the previous bottom water and the deeper part of the previous intermediate water (Figs. 7d and 8a). The upper part of the intermediate water body was pushed up over the intermediate clay. Relatively low heads at $\sim 65 \mathrm{~m}$ depth might have triggered the upward flow in the column which moved the high chemical gradients over the clay into the shallow subaquifer (Figs. 4a, b, f-h and 8a). Within the upper section, it looks as though there was also upward movement, raising the upper subaquifer's peaks in MLS2 (Figs. 4b-e, g and 8a).

The other "end member" flow regime would be lateral (horizontal) flow of different water bodies that pass through the observation well (Fig. 8b). The only assumption needed to explain the differences between MLS1 and MLS2 with this flow regime is the existence of chemically distinct water bodies throughout the entire depth of the aquifer. Magnitude and direction of lateral velocities at different depths might differ. 
Evidence of lateral flow of distinct water bodies through the monitoring well at $31.5 \mathrm{~m}$ b.g.l. $(\sim 13 \mathrm{~m}$ below the water table), which was observed by EC monitoring (Fig. 6), supports the lateral flow hypothesis. Water parcels with different chemical characteristics on a smaller scale ( $0-2 \mathrm{~m}$ below the water table) at a polluted site in the same aquifer were reported by Ronen et al. (1987). A lateral flow regime suggests that the intermediate water body in MLS2 was formed in a place in the aquifer where the $73-79 \mathrm{mb}$ b.g.l. clayey layer is absent; after flowing laterally into the clay-divided area of the aquifer, it exists both on top of, and below the clay layer (Fig. 8b). As mentioned in the site description (Sect. 2.1), clayey layers at these depths in this part of the aquifer are usually of continental origin can often be discontinuous over short distances. Therefore, the lateral flow explanation makes more sense than fast vertical flow across the clayey layer.

Further indirect evidence supporting the lateral flow "end member" is the lack of mass conservation within the water bodies: such mass conservation would be expected if we assume that the differences between the profiles occurred due to upward flow. Looking at the industrial-contaminant profiles (Fig. 4e, g and h), we observe large differences in concentrations between the top and intermediate water bodies in both MLS1 and MLS2, while the contaminant concentrations in the intermediate and bottom water bodies are similar. Focusing on the top water body, we see that whereas the mass of TCE and Cr increased significantly from MLS1 to MLS2, the mass of PCE decreased (Fig. 4e, g and $\mathrm{h}$ ). High TCE concentrations increased from $\sim 50000$ to $\sim 120000 \mu \mathrm{g}^{-1}$, whereas PCE concentrations decreased from $\sim 1800$ to $\sim 700 \mu \mathrm{g} 1^{-1}$, such that these changes cannot be explained by degradation of PCE to TCE. It is more likely that MLS1 and MLS2 sampled different water bodies with different contaminant characteristics due to their different lateral origin and history.

\subsection{Implications for sites with industrial contamination}

One of the most practical outcomes of this work is the idea that by sampling a single monitoring well via several consecutive MLSs, it is possible to arrive at a certain understanding of the spatial character of the subsurface contamination. This is because ambient water flow passes through the monitoring well and can be characterized. This information is very valuable in sites within cities where construction of monitoring wells is not a trivial undertaking, as it can be used to develop a site-specific monitoring network and remediation plan. For example, at the study site, a distinct difference between contamination extent in the upper and lower parts of the aquifer was apparent. In the upper part of the aquifer, the presence of distinct water bodies having limited horizontal and vertical extents suggests that the spacing between monitoring wells should be relatively small (on the order of tens of meters). In the lower part of the aquifer, contamination levels are much lower, such that the density of monitoring wells there can also be significantly lower.

Differences in contamination characteristics between the water bodies and their large degree of mobility can also impact both the selection of remediation technologies and cleanup progress. At the study site, for instance, remediation methods would need to be able to handle contaminants whose concentrations vary both spatially and temporally due to the movement of distinct water bodies. Apparent remedial progress may not be linear in such a system, not because the method does not work, but because background concentrations are changing due to the movement of distinct water bodies.

\section{Summary and conclusions}

Two sequential MLS campaigns were conducted in a $150-\mathrm{m}$ deep observation well penetrating the entire section of the Israeli Coastal Aquifer in Tel Aviv. Major ions, trace elements and VOCs were analyzed. The general characteristics of the chemical substance profiles were retained in the two sampling campaigns, performed 295 days apart, but a more detailed look showed significant differences (e.g. a change in the depths of major vertical concentration gradients). PCA of the chemical variables resulted in a first PC that was highly correlated with depth (PC1, $\sim 60 \%$ of the variability). PC2 ( $\sim 20 \%$ of the variability) was found to be associated with the variability caused by the different hydrochemical characteristics at the bottom of the aquifer, which caused sharp changes in the concentrations of some chemical variables. Three distinct depth-dependent water bodies were found in the PCAs of both MLS profiles. The two boundaries separating the three water bodies shifted upward between MLS1 and MLS2. A clay bed which divided the top and intermediate water bodies in MLS1 was entirely within the intermediate water body in MLS2. An evaluation of whether vertical or lateral flows were the most probable cause for this shift indicated that the latter is most likely. This conclusion was based on: (1) lateral flow ( $\left.v \sim 150 \mathrm{~m} \mathrm{yr}^{-1}\right)$ of distinct water bodies observed by continuous EC monitoring in a packed-off section; (2) lack of preservation of the contaminants' mass within the water bodies and different contamination characteristics in the two MLS profiles; (3) it is easier to explain the inconsistency of the water-body boundaries with stratigraphy in MLS2 by horizontal flow and limited lateral extent of the clayey bed, than by rapid vertical flow across this bed. This study's methods and findings are likely to be applicable to other contaminated sites in deep unconfined aquifers, particularly with respect to the usefulness of sequential multilevel observations from deep wells and the efficacy of PCA of this type of data. The fact that distinct water bodies of 10 to $100 \mathrm{~m}$ vertical and horizontal dimensions flow under such sites has implications for monitoring and remediation. 
Acknowledgements. This study was financed by the Israel Water Authority. The presented conclusions are those of the authors of this study.

Edited by: P. Grathwohl

\section{References}

Angelone, M., Cremisini, C., Piscopo, V., Proposito, M., and Spaziani, F.: Influence of hydrostratigraphy and structural setting on the arsenic occurrence in groundwater of the CiminoVico volcanic area (central Italy), Hydrogeol. J., 17, 901-914, 2009.

Assouline, S. and Shavit, U.: Effects of management policies, including artificial recharge, on salinization in a sloping aquifer: The Israeli coastal aquifer case, Water Resour. Res, 40, W04101, doi:10.1029/2003WR002290, 2004.

Brouyère, S., Carabin, G., and Dassargues, A.: Influence of injection conditions on field tracer experiments, Ground Water, 43, 389-400, 2005.

Cherry, A., Parker, B. L., and Keller, C.: A new depth-discrete multilevel monitoring approach for fractured rock, Ground Water Monit. R., 27, 57-70, 2007.

Ecker, A.: Atlas-selected geological cross sections and subsurface maps in the coastal aquifer of Israel, Report No. GSI/18/99, 151 pp., 1999 (in Hebrew).

Graber, E. R., Laor, Y., and Ronen, D.: Megasite aquifer contamination by chlorinated-VOCs: A case study from an urban metropolis overlying the coastal plain aquifer of Israel, Hydrogeol. J., 16, 1615-1624, doi:10.1007/s10040-008-0366-2, 2008.

Hendry, M. J., Barbour, S. L., Zettl, J., Chostner, V., and Wassenaar, L. I.: Controls on the long-term downward transport of $\delta^{2} \mathrm{H}$ of water in a regionally extensive, two-layered aquitard system, Water Resour. Res., 47, W06505, doi:10.1029/2010WR010044, 2011.

Issar, A.: Stratigraphy and paleoclimates of the Pleistocene of central and northern Israel, Palaeogeogr. Palaeocl., 29, 261-280, 1980.

Kurtzman, D., Nativ, R., and Adar, E.: The conceptualization of a channel network through macroscopic analysis of pumping and tracer tests in fractured chalk, J. Hydrol., 309, 241-257, 2005.

Kurtzman, D., Netzer, L., Weisbroad, N., Graber, E. R., and Ronen, D.: Steady-state homogenous approximations of vertical velocity from EC profiles, Ground Water, 49, 275-279, 2011.

Laor, Y., Ronen, D., and Graber, E. R.: Using a passive multilayer sampler for measuring detailed profiles of gas-phase VOCs in the unsaturated zone, Environ. Sci. Technol., 37, 352-360, 2003.

Moore, P. J., Martin, J. B., and Screaton, E. J.: Geochemical and statistical evidence of recharge, mixing, and controls on spring discharge in an eogenetic karst aquifer, J. Hydrol., 376, 443-455, 2009.
Müller, K., Vanderborght, J., Englert, A., Kemna, A., Huisman, J. A., Rings, J., and Vereecken, H.: Imaging and characterization of solute transport during two tracer tests in a shallow aquifer using electrical resistivity tomography and multilevel groundwater samplers, Water Resour. Res., 46, W03502, doi:10.1029/2008WR007595, 2010.

Nativ, R. and Weisbrod, N.: Hydraulic connections among subaquifers of the coastal plain aquifer, Israel, Ground Water, 32, 997-1007, 1994.

Netzer, L., Weisbrod, N., Kurtzman, D., Nasser, A., Graber, E. R., and Ronen, D.: Observations on vertical variability in groundwater quality: Implications for aquifer management, Water Resour. Manag., 25, 1315-1324, 2011.

Pitrak, M., Mares, S., and Kobr, M.: A Simple borehole dilution technique in measuring horizontal ground water flow, Ground Water, 15, 89-92, 2007.

Ronen, D., Magaritz, M., and Levy, I.: A multi-layer sampler for the study of detailed hydrochemical profiles in groundwater, Water Res., 20, 311-315, 1986.

Ronen, D., Magaritz, M., Gvirtzman, H., and Garner, W.: Microscale chemical heterogeneity in groundwater, J. Hydrol. , 92, 173-178, 1987.

Ronen, D., Graber, E. R., and Laor, Y.: Volatile organic compounds in the saturated-unsaturated interface region of a contaminated phreatic aquifer, Vadose Zone J., 4, 337-344, 2005.

Ronen, D., Netzer, L., Nasser, A., Weisbrod, N., Kurtzman, D., and Graber, E. R.: Assessment of aquifer contamination in the Nahalat Itzhak area - Tel Aviv: Phase iii - final report, Israel Water Authority, 2010.

StatSoft Inc.: Electronic statistics textbook, available at: http://www.Statsoft.Com/textbook/ principal-components-factor-analysis/?Button=1, StatSoft, Inc., Tulsa, OK, USA, 2011.

Stetzenbach, K. J., Farnham, I. M., Hodge, V. F., and Johannesson, K. H.: Using multivariate statistical analysis of groundwater major cation and trace element concentrations to evaluate groundwater flow in a regional aquifer, Hydrol. Process., 13, 26552673, 1999.

Williams, B. A. and Chou, J. C.: Characterizing vertical contaminant distribution in a thick unconfined aquifer, Hanford site, Washington, USA, Environ. Geol., 53, 879-890, doi:10.1007/s00254-007-0700-3, 2007.

Zilberbrand, M., Rosenthal, E., and Shachnai, E.: Impact of urbanization on hydrochemical evolution of groundwater and on unsaturated-zone gas composition in the coastal city of Tel Aviv, Israel, J. Contam. Hydrol., 50, 175-208, 2001. 